\title{
Regional ionospheric modeling using wavelet network model
}

\author{
Mohammed El-Diasty ${ }^{1,2}$
}

\begin{abstract}
A major error component of Global Positioning System (GPS) is the ionospheric delay. lonopspheric error can be reduced by a dual frequency receiver using a linear combination technique that can not be applied with a single frequecy receiver. However, an accurate ionospheric error modeling for single-frequency receiver is required. Due to the nonlinearity of the ionospheric error, a highly nonlinear wavelet network (WN) method is proposed in this paper. The main objective of the paper is to develop a short-term prediction model based on a short dataset. Therefore, five GPS stations with five days of ionospheric datasets along with time and location were employed to develop the proposed WN-based ionospheric model. Four days of datasets were employed to develop the model and one day of dataset was employed to test the prediction accuracy. To validate the WN-based ionospheric model, a comparison was made between the developed WN-based ionospheric model and the CODE, JPL and IGS Global lonospheric Map (GIM) models. It is shown that the Root-Mean-Squared (RMS) errors of the developed WNbased ionospheric model are 2.51 TECU, 2.75 TECU and 2.50 TECU (Total Electronic Content Unit) with percentage errors of about 3.4\%, 3.8\% and 3.4\% when compared with the CODE, JPL and IGS GIM models.
\end{abstract}

Keywords: GPS, Ionospheric delay, Wavelet network, Total electron content (TEC), GIM model

\section{Introduction}

Global Positioning System (GPS) satellites broadcast radio signals in $L$ frequency band and are subject to important distortions while crossing the ionosphere. The ionospheric delay is due to the electron concentration in the ionosphere layers. It varies during the day with the ionisation of the particles hit by sun rays. It is a consequence of the dispersive nature of the medium, which causes sinusoidal waves with different frequencies to travel at slightly different velocities. As a result, the satellite signal is submitted to a group delay and a phase advance of identical amplitudes. The ionospheric delay $I$ is computed as a function of the electron content along the signal trajectory through the ionosphere as follows (Misra and Enge 2006):

$$
I=\frac{40.3 * T E C}{f^{2}}
$$

Correspondence: mkandeel@kau.edu.sa

${ }^{1}$ Department of Hydrographic Surveying, Faculty of Maritime Studies, King Abdulaziz University, Jeddah, Saudi Arabia

${ }^{2}$ Engineering Department of Public Works, Faculty of Engineering, Mansoura University, Mansoura, Egypt

\section{Springer Open}

$$
T E C=\int_{S} n_{e}(S) d S
$$

where $d$ is the distance delay $(\mathrm{m})$ in comparison to the propagation in vacuum, TEC is the electron concentration determined along the oblique trajectory (total electron content for the concerned path in $\mathrm{el} / \mathrm{m} 2$ ), $f$ is signal frequency $(\mathrm{Hz}), \mathrm{S}$ is the path from the transmitter to the receiver $(\mathrm{m})$ and $n$ is the electron density $(\mathrm{el} / \mathrm{m} 3)$.

The equation here above only considers the first order effect of ionosphere on signals propagation. The ionospheric delay mathematical representation is actually a limited development. According to the need of precision in the expression of the ionospheric delay the second order effect and the third order effect may be taken into account. The second $\left(1 / \mathrm{f}^{3}\right)$ and third order effect $\left(1 / \mathrm{f}^{4}\right)$ are functions of the plasma frequency, the electrons gyrofrequency and the direction of the wave with relation to the magnetic field. In most of the cases only the first order effect is considered to assess the ionospheric delay. In the case of GPS signals, the second order effect is typically of a magnitude of a few centimeters, while the third order effect has a typical magnitude of some millimeters. 
All of the GPS errors can be corrected to some extent by implementing model algorithms depending on the applications. A major error component of GPS positioning is the ionospheric delay. However, unlike other GPS errors, ionospheric delay correction is hard and complex to model because the ionosphere shows both spatial and temporal behavior. Ionopspheric error can be reduced by a dual frequency receiver using a linear combination technique that can not be applied for a single frequecy receiver. Operationally for single-frequency receiver, the Klobuchar model is employed to correct for ionospheric error, however, the Klobuchar model permits to correct about $50 \%$ of the ionospheric error for mid-latitudes location and average ionospheric environment (Klobuchar, 1975). Therefore, the ionospheric modeling has been investigated for last few decades to develop an accurate ionospheric correction for single-frequency receiver. Currently, GPS analysis centers provide GIMs (Global Ionosphere Maps) on a daily basis. The widely used GPS-derived GIMs are provided by the Center for Orbit Determination in Europe (CODE), the Jet Propulsion Laboratory (JPL) and the International GNSS Service (IGS) with a spatial resolution of $2.5^{\circ}$ and $5.0^{\circ}$ in latitude and longitude, respectively, and a 2-h temporal resolution (Komjathy 1997; Feltens and Jakowski 2002). However, the Global Ionospheric Map (GIM) models (GIM) models such as CODE, JPL and IGS GIM models cannot reproduce local, short-lasting processes in the ionosphere. In addition, the resolution of these products might not be sufficient to support high quality GPS positioning, especially in the presence of local ionospheric disturbances. The need to produce regional ionosphere models for accurate positioning was investigated by many researchers (Komjathy and Langley, 1996; HernándezPajares et al., 1997; Hernandez- Pajares et al. 1999; Liu and Gao, 2003; Wielgosz et al., 2003; Moon,
2004; Leandro and Santos 2007; Sayin et al., 2008; Maruyama, 2007; Liu et al., 2011; Liu et al., 2014; Ohashi et al., 2015 and Razin et al., 2015), where different algorithms were employed for regional ionosphere modeling such as Spherical harmonics, Spline interpolation, Gaussian process, kriging and artificial neural networks. However, due to the nonlinearity of ionosphere physical properties a highly nonlinear model a highly nonlinear wavelet network method is proposed in this paper to model and predict the temporal and spatial variations of ionosphere modeling. The main objective of the paper is to develop a short-term prediction model based on a short dataset. Therefore, five GPS stations with five days of ionospheric datasets along with time and location with 15 min sampling rate are employed to develop the proposed WN-based ionospheric model. Four days of datasets are employed to develop the model and one day of dataset is employed to test the prediction accuracy. Also, a comparison is made between the proposed wavelet network based ionospheric model and the well-established CODE, JPL and the IGS Global Ionospheric Map (GIM) models.

\section{Ionospheric delay estimation}

The major range error for GPS measurements is mainly due the deviation of the speed of the signal from its actual light speed because of the presence of free electrons in the ionosphere medium. This medium is extended from $50 \mathrm{~km}$ to about $1000 \mathrm{~km}$ above the earth surface. The variations of the ionospheric effects are mainly governed by the ionization processes, which is caused by the solar radiation. Hence there is a direct relationship and the state of the ionosphere can be realized by observing the intensity of the solar activity. The physical characteristics of the ionosphere have noticeable diurnal (day and night) variations. During the sun rise, the

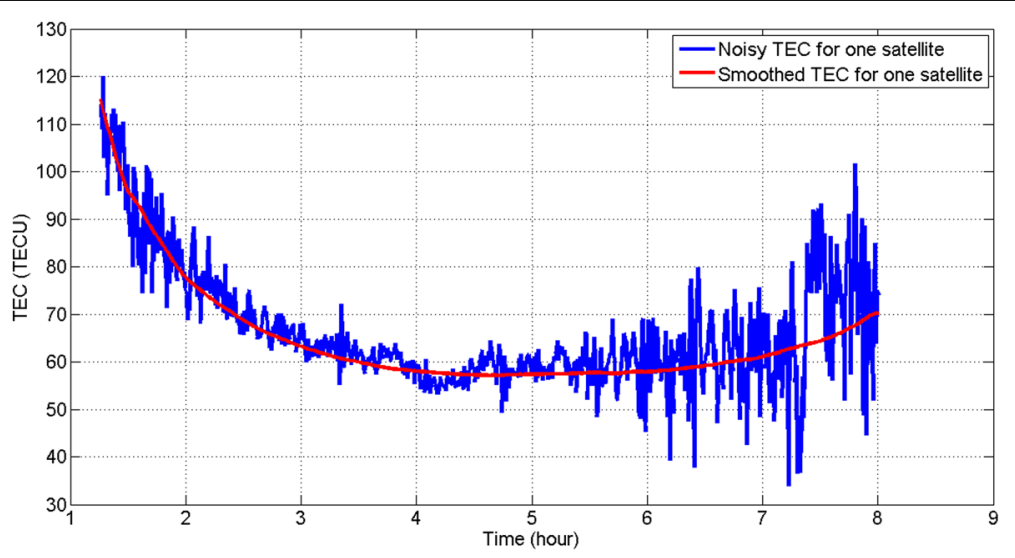

Fig. 1 Estimated noisy and smoothed TEC for one satellite 


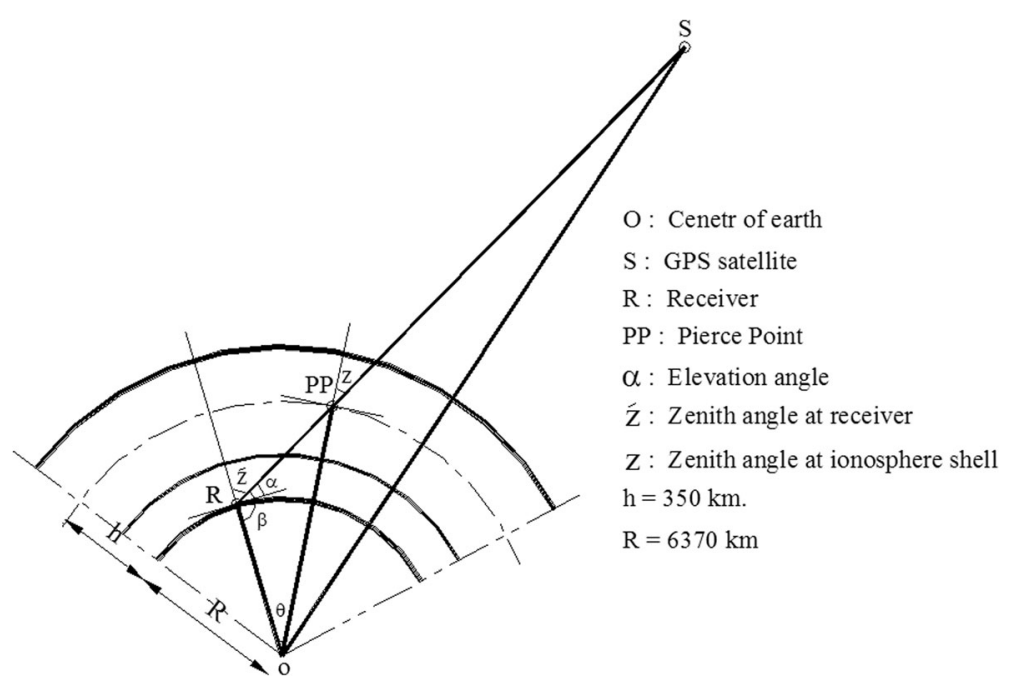

Fig. 2 lonospheric shell and different angles

electron density starts to build up due to the ultraviolet radiations which help to break up gas molecules into ions and free electrons (Leick, 2004; HofmannWellenhof et al., 2008).

Single-frequency receivers can access eight ionospheric coefficients, located in the GPS navigation message to estimate the ionospheric delay based on the Klobuchar model. These coefficients are generated at least once per 6 days but no more than once a day and they are updated by the 5 GPS Ground Control Segment stations. The Klobuchar algorithm is a physical model that considers the changes in latitude, season, solar flux and magnetic activity representing the amplitude change along with the associated diurnal period change of the ionospheric delay. The Klobuchar model permits to correct about $50 \%$ of the ionospheric error for mid-latitudes location and average

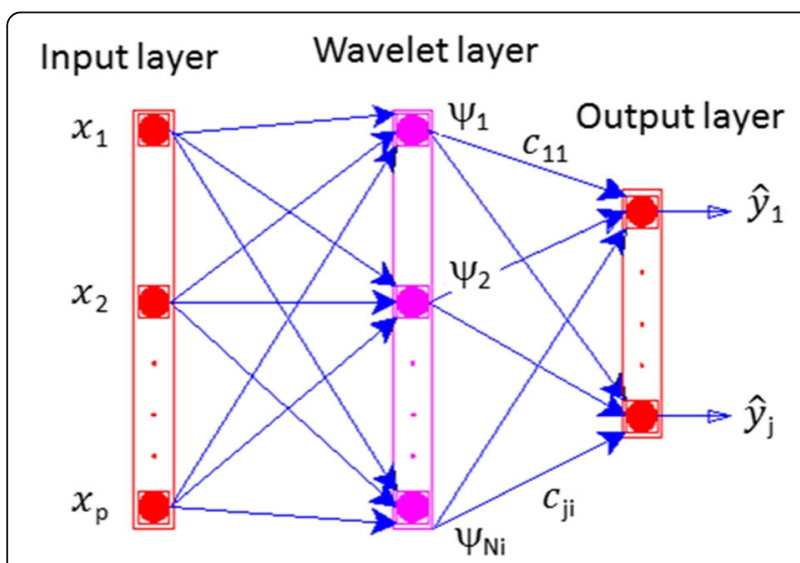

Fig. 3 General Wavelet Network Structure (Nm-input, Ni-wavelons, and $\mathrm{Nj-outputs).} \mathrm{Blue} \mathrm{arrows} \mathrm{indicate} \mathrm{the} \mathrm{weights} \mathrm{parameters} \mathrm{for} \mathrm{the}$ connected layers ionospheric environment. Therefore, the ionospheric modeling has been investigated for last few decades to develop an accurate ionospheric correction for single-frequency receiver applications. To develop a regional ionospheric model, the ionospheric error is estimated using dual frequency receivers distributed in the area under consideration as discussed below.

GPS signals are transmitted in two $L$ frequency bands ( $L 1$ and $L 2$ ) and a dual frequency receiver can be used to provide code measurements $\left(P_{f 1}\right.$ and $\left.P_{f 2}\right)$ and carrierphase measurements $\left(\phi_{f 1}\right.$ and $\left.\phi_{f 1}\right)$. The receiver is able to assess the ionospheric delay on $f 1$ using code measurements combination $I_{P-f 1}$ or using carrier-phase measurements combination $I_{\phi-f 1}$ of identical amplitudes as follows (Hofmann-Wellenhof et al., 2008):

$$
\begin{gathered}
I_{P-f 1}=\frac{\left(P_{f 1}-P_{f 2}\right) \cdot f_{2}^{2}}{f_{2}^{2}-f_{1}^{2}} \\
I_{\phi-f 1}=\frac{\left(\phi_{f 2}-\phi_{f 1}\right) \cdot f_{2}^{2}}{f_{2}^{2}-f_{1}^{2}}
\end{gathered}
$$

The integration of the above code measurements combination and carrier-phase measurements combination along with the ionospheric delay from equation (1) can produce the smoothed value of the TEC as follows:

$$
\begin{aligned}
& \text { TEC }=\frac{1}{40.3}\left(\frac{1}{f_{1}^{2}}-\frac{1}{f_{2}^{2}}\right)^{-1} \\
& \left(\left(\phi_{f 2}-\phi_{f 1}\right)-\left(\phi_{f 2}-\phi_{f 1}\right)_{0}+\left(P_{1}-P_{2}\right)_{0}\right) \quad\left(e l / m^{2}\right)
\end{aligned}
$$

where $\left(\phi_{f 2}-\phi_{f 1}\right)_{0}$ and $\left(P_{1}-P_{2}\right)_{0}$ are the initial values of the carrier-phase measurements 


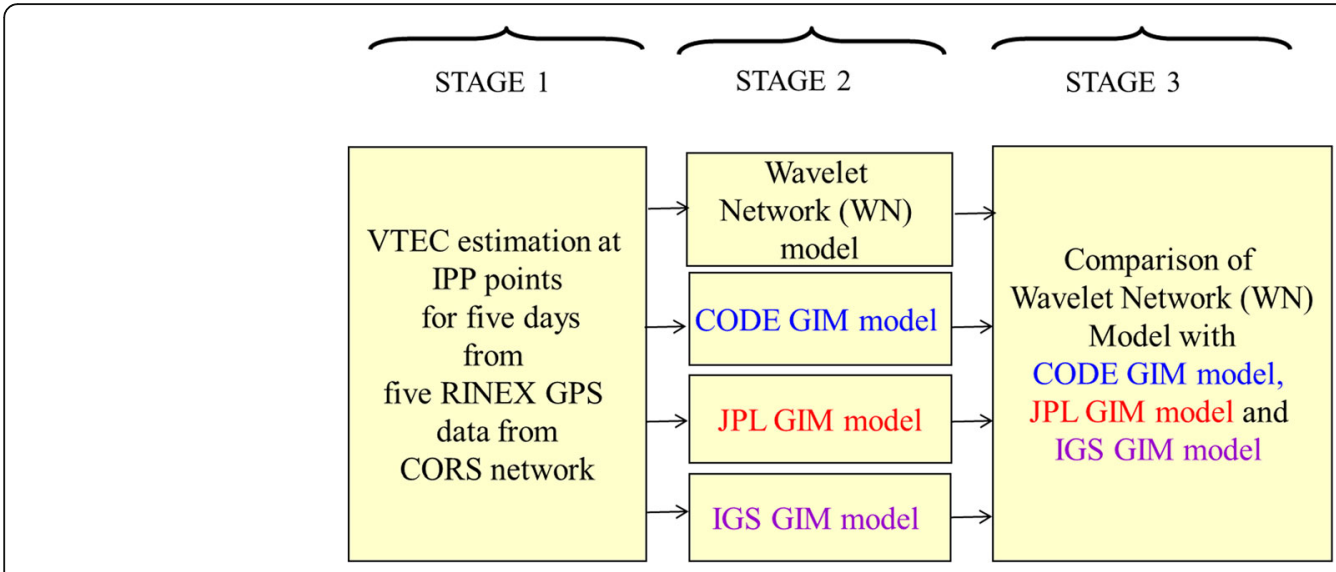

Fig. 4 Methodology

combination and code measurements combination, respectively, and $e l$ is the number of electrons. Fig. 1 shows an example of a noisy and smoothed TEC for one satellite.

The ionospheric delay is estimated at the ionosphere pierce point (IPP) that is defined as the intersection between the constant ionosphere ellipsoid $(350 \mathrm{~km}$ above the WGS84 ellipsoid) and the line in view from the receiver antenna reference point to the satellite antenna reference point. Fig. 2 shows he cross-section of main components; Earth, receiver, ionosphere shell, satellite and their spatial relationship. If the elevation angle

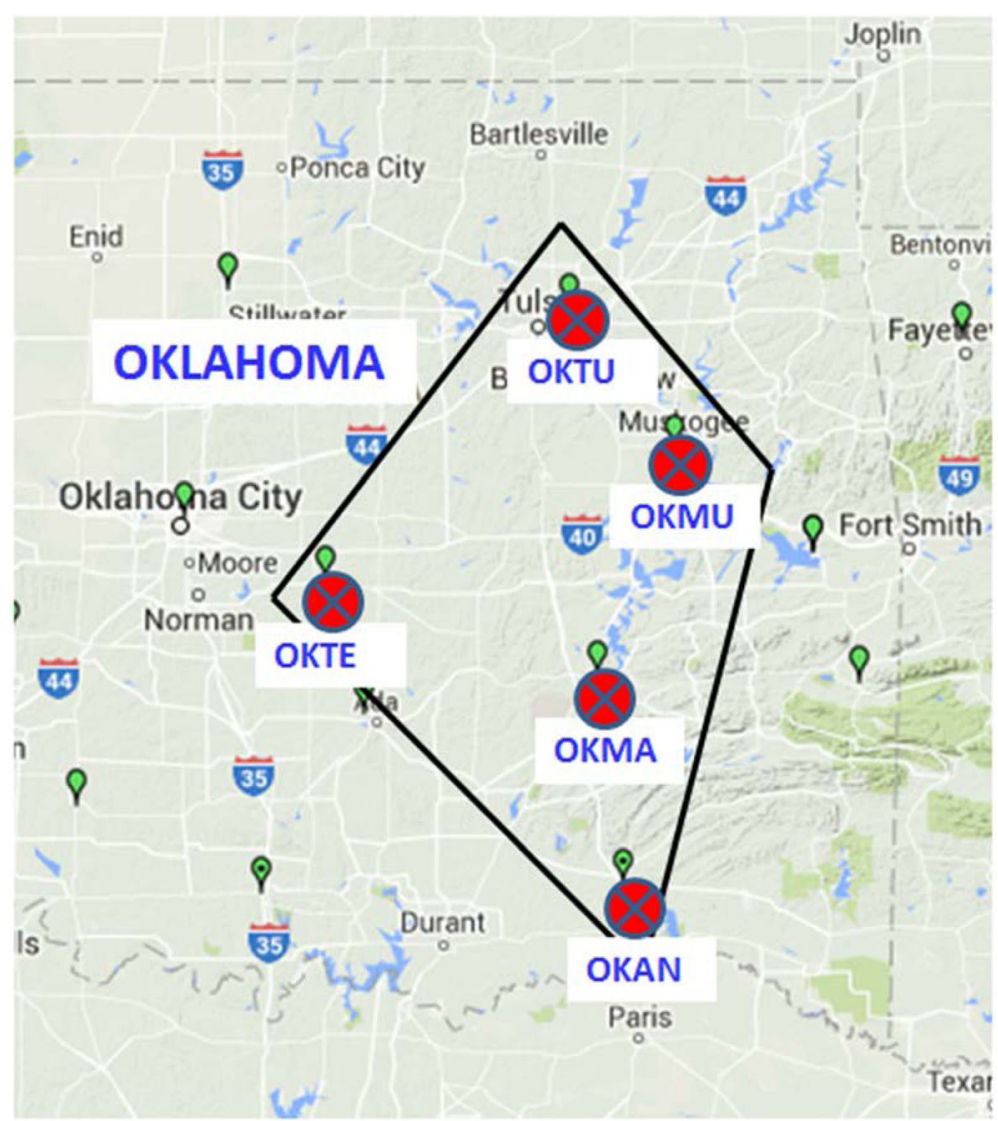

Fig. 5 The geographic location for OKTU, OKTE, OKAN, OKMA and OKMU stations from the CORS map 


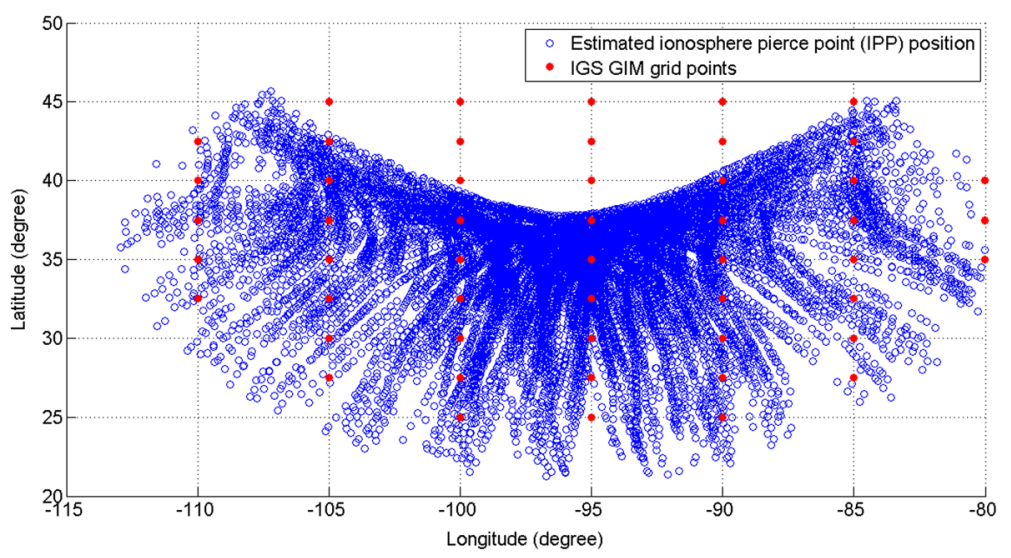

Fig. 6 The estimated IPP positions and the GIM grid points located in the study area

of a satellite $(\alpha)$ is estimated, the Zenith angle at receiver $\left(z^{\prime}\right)$ and the Zenith angle at IPP $(z)$ can be estimated as follows:

$$
\begin{aligned}
& z^{\prime}=90^{\circ}-\alpha \\
& z=\sin ^{-1}\left(\frac{R \cdot \sin \left(z^{\prime}\right)}{R+h}\right)
\end{aligned}
$$

It is worth noting that an appropriate cut-off angel is used to ignore those satellites with bad geometry and under horizon level (Hofmann-Wellenhof et al., 2008).

In practice, the ionospheric model is developed using the vertical total electron content (VTEC) that should be estimated at the IPP. Using a simple geometric function, vertical Total Electron Content can be estimated as:

$$
V T E C=T E C \times \operatorname{Cos}(z)
$$

where $z$ is the zenith angle at pierce point.

In this paper, the wavelet network model is proposed to model the estimated VTEC form a number of GPS receivers in a regional area and the model was validated by the Global Ionospheric Model (GIM) developed by the CODE analysis center.

\section{Wavelet network model}

The wavelet network is an efficient method for data modeling. Zhang and Benveniste (1992) proposed the algorithms of the wavelet network methodology. Afterward, several researchers extended their studies to improve the wavelet network procedure for parameter estimation and learning algorithms (Zhang, 1997). Also, the application of the wavelet network in modeling and prediction has been implemented in several areas of studies such as El-Diasty et. al (2007), Oussar et al. (1998) and Adeli and Samant (2000). It is worth noting that no studies have implemented wavelet networks in regional ionospheric modeling and prediction. A wavelet network is an algorithm connects the neural network with the wavelet decomposition that leads to a wavelet network structure with the highly nonlinear wavelet function. In this research, the

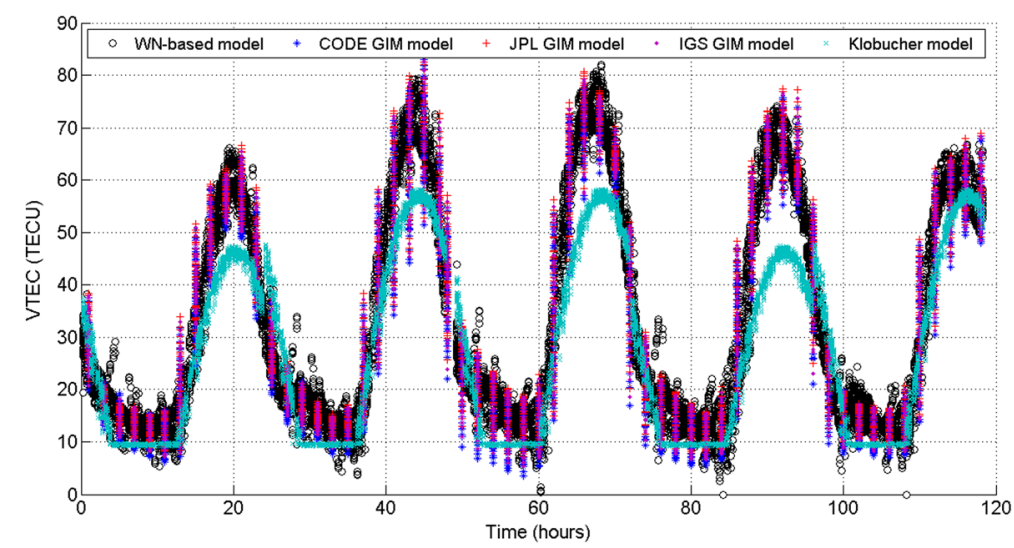

Fig. 7 The trained (modeled - four days) and tested (predicted - one day) WN-based VTEC values compared with the CODE GIM model, JPL GIM model, IGS GIM model and the Klobucher model 


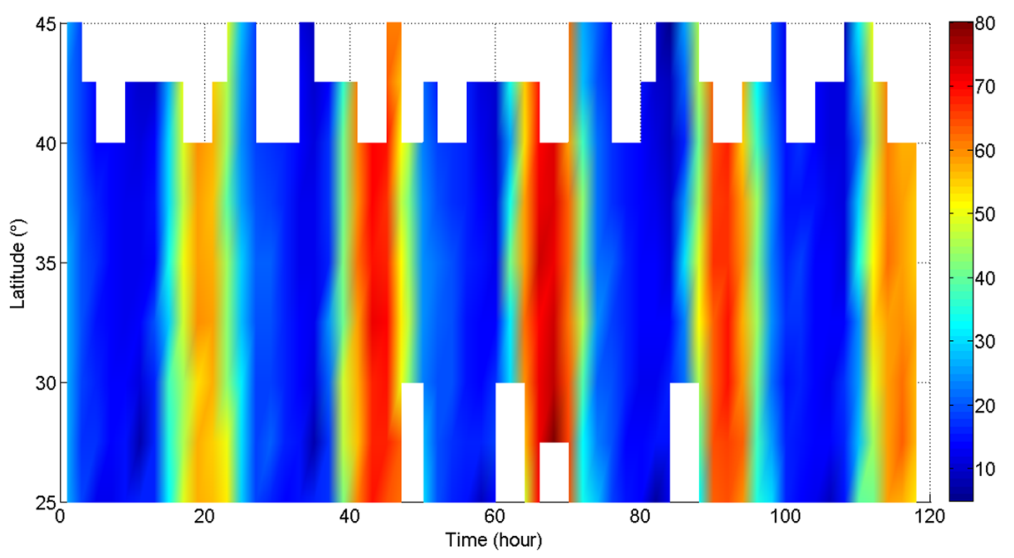

Fig. 8 The map shows diurnal variations of the WN-based VTEC values (TECU) in a timelatitude domain

tidal height prediction model is developed using wavelet network model with an output $\hat{y}_{k}$ computed as:

$$
\hat{y}_{k}=\sum_{m=1}^{N_{m}} c_{i} \Psi\left(a_{m}\left(x_{m}^{k}-b_{m}\right)\right)+w
$$

where $x_{m}^{k}$ is the input neuron, $c_{i}$ are coefficient variables, $a_{m}$ are dilation variables, $b_{m}$ are translation variables, and $\Psi$ is a wavelet function. Fig. 3 shows the wavelet network structure. The wavelet network consists of an input vector of $N_{m}$ values, a layer of $N_{i}$ weighted wavelets and an output vector of $N_{k}$ output neurons. The wavelet network parameters $\left(c_{i}, a_{m}\right.$, and $\left.b_{m}\right)$ can be estimated by a backpropagation-learning method (Haykin 1999; Lekutai, 1997; Zhang and Benveniste, 1992).

If $N_{k}$ is the number of outputs, $y_{k}^{d}$ is the desired output values and $\hat{y}_{k}$ is the network output estimated from Eqn. (9), then, the wavelet network training objective is to minimize the error function, $E$ (Haykin 1999; Lekutai 1997; Zhang and Benveniste, 1992):

$$
E=\frac{1}{2} \sum_{k=1}^{N_{k}}\left(y_{k}^{d}-\hat{y}_{k}\right)
$$

The selection of the wavelet function depends on the application. There are several wavelet functions that can be utilized to develop the wavelet network model such as Morlet, Shannon and Mexican hat. We use the Mexican hat in this research to implement the proposed nonlinear regional ionospheric model. The Mexican hat wavelet function for any variable $x$ is:

$$
\Psi(x)=\left(\|x\|^{2}-p\right) e^{-\frac{\|x\|^{2}}{2}},
$$

where, $\|x\|^{2}=x^{\mathrm{T}} x$, and $p$ is the order of the model (12)

The Mexican hat wavelet function is known as Laplacian operator and represents the second derivative of the Gaussian function (Percival and Walden, 2000). The root-mean-squared (RMS) is commonly used to evaluate the model performance. The RMS error can be computed as:

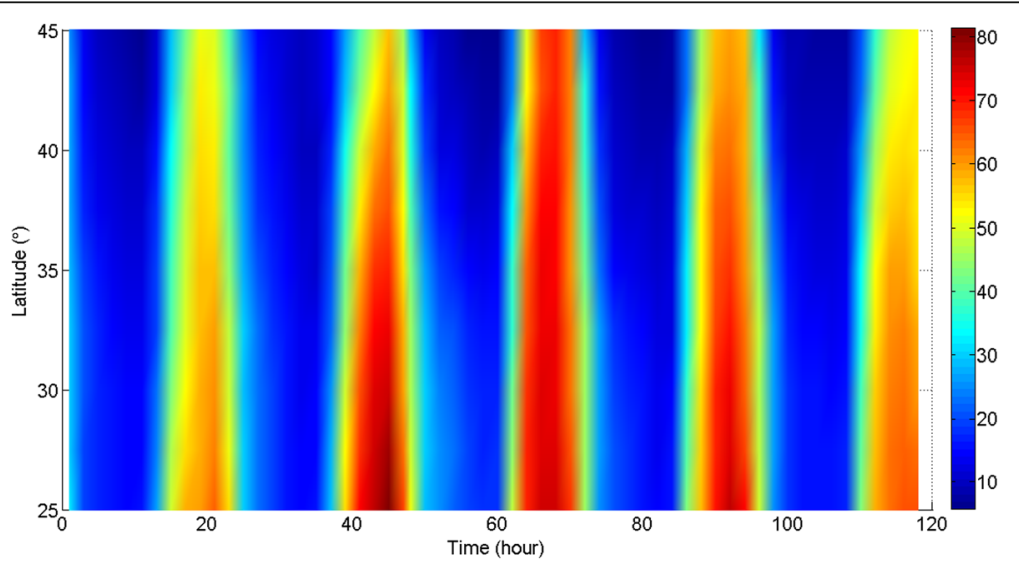

Fig. 9 The map shows diurnal variations of the IGS GIM VTEC values (TECU) in a timelatitude domain 


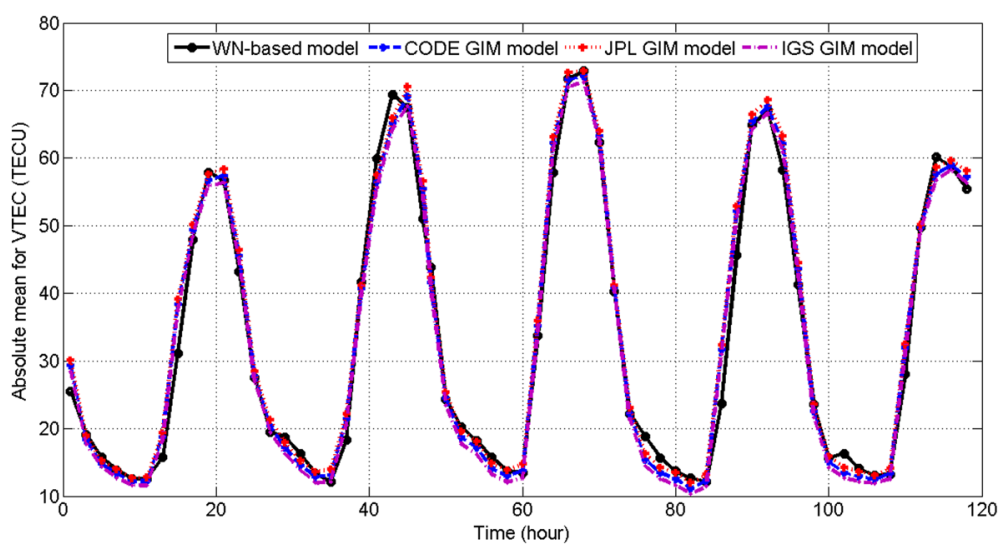

Fig. 10 The absolute mean of the WN-based VTEC values compared with the CODE, JPL and IGS GIM models

$$
R M S=\sqrt{\frac{\left(\sum_{j=1^{N j}} \sum_{k=1}^{N_{k}}\left(y_{k j}^{d}-\hat{y}_{k j}\right)\right)^{2}}{N_{k} \cdot N_{j}}}
$$

The structure of the wavelet network is determined by empirical methods. The number of neurons can be determined by training different architectures with different number of neurons to select the optimal number, based on the lowest RMS error (El-Diasty et al. 2007). It should be noted that the dilation and transition properties of the wavelet function make the wavelet network much more dynamic, flexible, robust, and promising methodology for regional ionospheric modeling and prediction than traditional artificial neural network method.

\section{Methods}

The wavelet network method regional ionospheric modeling and prediction was implemented over three major stages as shown in Fig. 4. The implementation of these three stages was performed through; 1) Data preparation stage, 2) Ionospheric modeling and prediction stage and 3) comparison stage. In the first stage, the estimated VTEC for five days long from five RINEX GPS data from the USA CORS network were obtained. In the second stage, a wavelet network model was developed and the well-established CODE, JPL and the IGS Global Ionospheric Map (GIM) models were employed to estimate the VTEC for the regional area under investigation. Then in the third stage, a comparison was made between the developed wavelet network model and the well-established CODE, JPL and the IGS Global Ionospheric Map (GIM) models.

The VTEC were estimated for five days long from five GPS CORS stations in Oklahoma, USA, namely OKTU, OKTE, OKAN, OKMA and OKMU were used to implement the proposed wavelet network model and compare the results with the CODE and JPL GIM models. Fig. 5 shows the geographic location for OKTU, OKTE, OKAN, OKMA and OKMU stations from the CORS map.

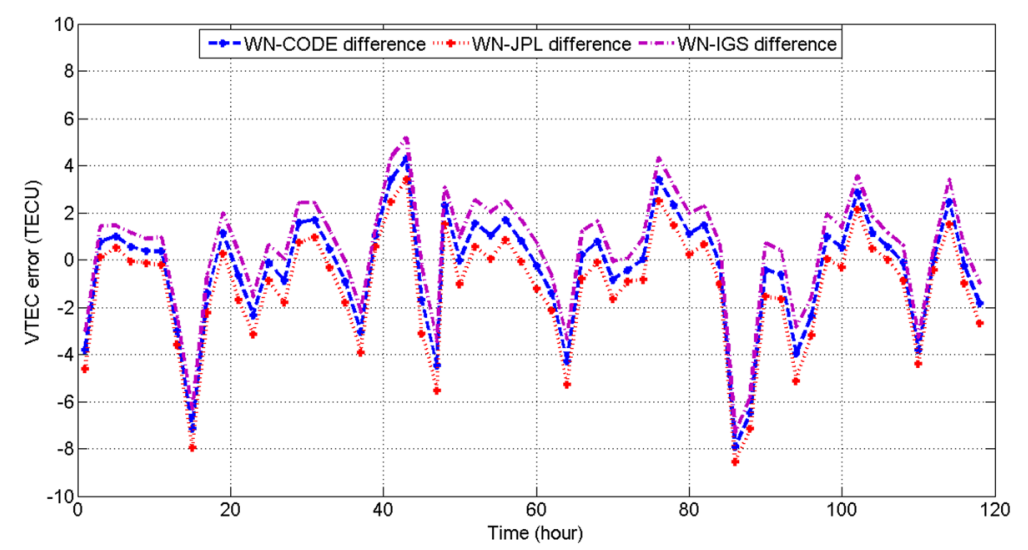

Fig. 11 The errors (the difference between the absolute mean of modeled VTEC values) from WN-based model when compared with the CODE, JPL and IGS GIM models 
Table 1 The summary statistical results when the absolute VTEC mean estimated from wavelet network model is compared with the ones estimated from CODE, JPL and IGS GIM models for training dataset (4 days)

\begin{tabular}{llll}
\hline Statistical parameter & $\begin{array}{l}\text { WN-based model versus } \\
\text { CODE GIM model }\end{array}$ & $\begin{array}{l}\text { WN-based model } \\
\text { versus JPL GIM model }\end{array}$ & $\begin{array}{l}\text { WN-based model } \\
\text { versus IGS GIM model }\end{array}$ \\
\hline $\begin{array}{l}\text { Correlation between the } \\
\text { WNbased model and GIM model }\end{array}$ & $87.9 \%$ & $86.7 \%$ & $87.7 \%$ \\
RMS error between the & 2.51 TECU & 2.75 TECU & 2.50 TECU \\
$\begin{array}{l}\text { WNbased model and GIM model } \\
\text { ercentage of error }\end{array}$ & $3.4 \%$ & $3.8 \%$ & $3.4 \%$ \\
Absolute VTEC error bias & 1.95 TECU & 1.90 TECU & 1.78 TECU \\
Absolute VTEC maximum error & 7.9 TECU & 8.54 TECU & 7.3 TECU \\
\hline
\end{tabular}

The structure of the wavelet network was built using the Matlab software version 2010. Many wavelet network models were carried out to optimize the structure of the wavelet network using four days of dataset to build the model and one day of dataset to test (prediction mode) the proposed WN-based model. It was found that the wavelet network with the structure [5-90-1] provides the best solution with the lowest root-meansquare (RMS) error. The input layer of five values that represent first input of the day number (one to five), second input of the time of the day (from 0 to 24 in $15 \mathrm{~min}$ interval), third input of the latitude of the IPP point (in radians), fourth input of the longitude of the IPP (in radians) and fifth input of the estimated Klobuchar model at same IPP point. The hidden layer of 90 wavelet neurons (wavelons) was employed to model the desired VTEC value.

\section{Results and discussion}

In this section, the results of the developed wavelet network model are investigated and a comparison was made between the developed wavelet network based model and the CODE, JPL and the IGS Global Ionospheric Map (GIM) models. It should be noted that the IGS GIM model is a combination of GIM models provided by several analysis centers. All the analysis centers involved may use different approaches to the VTEC derivation from GPS observations, as well as different VTEC representation/modeling techniques. The spatial resolution of the GIM model is $2.5^{\circ}$ in latitude and $5.0^{\circ}$ in longitude. For comparison purposes, a regional model was extracted from and the CODE, JPL and the IGS GIM models. Fig. 6 shows the estimated IPP positions and the extracted GIM model grid points located in the regional study area.

At the beginning, the estimated VTEC values from the WN-based model, CODE GIM model, JPL GIM model, IGS GIM model and the Klobucher model were investigated. Fig. 7 shows the VTEC values estimated from WN-based model, CODE GIM model, JPL GIM model, IGS GIM model and the Klobucher model in time domain. Then, the VTEC values from the WN-based model, CODE GIM model, JPL GIM model and IGS GIM model were estimated in time and latitude domain. Figs. 8 and 9 show the VTEC values from the WN-based model and IGS GIM model, respectively. It can be seen that the two models show similar diurnal variations in time domain at the same time slots. The other two CODE and JPL GIM models showed similar results as of the IGS GIM model and therefore are not shown in this paper. It should be noted that the gaps in the $\mathrm{WN}$ based model represented the areas with no IPP points during the five days of GPS observations under investigation. Afterwards, the overall performance of the VTEC values from the WN-based model, CODE, JPL and IGS GIM models were investigated. Fig. 10 shows the absolute mean of the VTEC values estimated from the developed WN based model when compared with the CODE, JPL and IGS GIM models. Fig. 11 shows

Table 2 The summary statistical results when the absolute VTEC mean estimated from wavelet network model is compared with the ones estimated from CODE, JPL and IGS GIM models for testing (prediction) dataset (1 day)

\begin{tabular}{llll}
\hline Statistical parameter & $\begin{array}{l}\text { WN-based model } \\
\text { versus CODE GIM model }\end{array}$ & $\begin{array}{l}\text { WN-based model } \\
\text { versus JPL GIM model }\end{array}$ & $\begin{array}{l}\text { WN-based model } \\
\text { versus IGS GIM model }\end{array}$ \\
\hline $\begin{array}{l}\text { Correlation between the } \\
\text { WNbased model and GIM model }\end{array}$ & $88.12 \%$ & $86.5 \%$ & $88.5 \%$ \\
$\begin{array}{l}\text { RMS error between the } \\
\text { WNbased model and GIM model }\end{array}$ & 2.50 TECU & 2.83 TECU & 2.40 TECU \\
$\begin{array}{l}\text { Percentage of error } \\
\text { Absolute VTEC error bias }\end{array}$ & $3.60 \%$ & $4.2 \%$ & $3.4 \%$ \\
Absolute VTEC maximum error & 1.78 TECU & 2.03 TECU & 1.89 TECU \\
\hline
\end{tabular}


the errors (the difference between the absolute mean of modeled VTEC values) from developed WN based model when compared with the CODE, JPL and IGS GIM models. Tables 1 and 2 illustrate the summary statistical results when the absolute VTEC mean estimated from developed $\mathrm{WN}$ based model compared with the ones estimated from CODE, JPL and IGS GIM models for the trained (four days) and the tested (prediction mode for one day) datasets. It can be seen from Tables 1 and 2 that the RMS errors are about 2.51 TECU, 2.75 TECU and 2.50 TECU (Total Electronic Content Unit) when the WN-based model compared with the CODE, JPL and IGS GIM models. It is also shown from Tables 1 and 2, and Fig. 11 that the percentage of the $\mathrm{WN}$-based model error is about $3.4 \%, 3.8 \%$ and $3.4 \%$ when WN-based model compared with the CODE, JPL and IGS GIM models and with a maximum absolute error of about 7.17 TECU, 8.17 TECU and 5.74 TECU, respectively. Therefore, in practice the developed WN model can be used for real-time regional ionospheric modeling for accurate GPS positioning with a single frequency GPS receiver and can reduce the ionospheric error with about $96 \%$ in average. It is worth noting that the accuracy of the developed short-term WN-based model agrees well with the most recent modeling methods of regional TEC such as spherical cap harmonic analysis model (Liu et al., 2011; Liu et al., 2014), despite the use of short datasets.

\section{Conclusion}

The main objective of the paper is to develop a short-term prediction model based on a short dataset. An ionospheric model using a wavelet network method was proposed and developed in this paper. GPS data from five stations for five days long were used to implement and validate the proposed model. The wavelet network structure of 5-901 gave the best performance solutions (i.e., the minimum RMS), and therefore was used in modeling the VTEC values. It is shown that the Root-Mean-Squared (RMS) errors of the developed WN-based ionospheric model are 2.51 TECU, 2.75 TECU and 2.50 TECU (Total Electronic Content Unit) with percentage errors of about 3.4\%, 3.8\% and $3.4 \%$ when compared with the CODE, JPL and IGS GIM models and with a maximum absolute error of about 7.17 TECU, 8.17 TECU and 5.74 TECU, respectively. Therefore, in practice the developed WN model can be used for real-time regional ionospheric modeling for accurate GPS positioning with a single frequency GPS receiver and can reduce the ionospheric error with about $96 \%$ in average.

\section{Competing interest}

The author declare that they have no competing interests

\section{Publisher's Note}

Springer Nature remains neutral with regard to jurisdictional claims in published maps and institutional affiliations.

Received: 16 November 2016 Accepted: 11 May 2017

Published online: 22 May 2017

\section{References}

Adeli H, Samant A (2000) An adaptive conjugate gradient neural network-wavelet model for traffic incident detection. Comput Aided Civ Inf Eng 15(4):251-260

El-Diasty M, El-Rabbany A, Pagiatakis S (2007) An accurate nonlinear stochastic model for MEMS-based inertial sensor error with wavelet networks. J Appl Geodesy 1(4):201-212

Feltens J, Jakowski N (2002), International GPS Service (IGS) lonosphere Working Group Activity, SCAR Report No 21, SCAR Working Group on Geodesy and Geographic Information, Russia, 18 -20 July

Haykin S (1999) Neural Networks: A Comprehensive Foundation, 2nd edn. Prentice Hall, Englewood Cliffs

Hernández-Pajares M, Juan JM, Sanz J (1999) New approaches in global ionospheric determination using ground GPS data. J Atmos Sol Terr Phys 61: 1237-1247

Hernández-Pajares M, Juan J, Sanz J (1997) Neural network modeling of the ionospheric electron content at global scale using GPS data. Radio Sci 32(3): 1081-1089. doi:10.1029/97RS00431

Hofmann-Wellenhof B, Lichtenegge H, Walse E (2008) GNSS Global navigation satellite systems; GPS, glonass, Galileo \& more. Springer Wien, New York

Klobuchar J (1975) A first-order worldwide ionospheric time delay algorithm. Air Force Cambridge Research Laboratories Hanscom AFB MA AFCRL-TR-75-0502 AD A018862

Komjathy A (1997) Global lonospheric total electron content mapping using the global positioning system, Ph.D. Dissertation, department of geodesy and geomatics engineering technical report No. 188. University of New Brunswick, Canada, p 248

Komjathy A, Langley R (1996) An assessment of predicted and measured ionospheric total electron content using a regional GPS network, Proceedings of the national technical meeting of the institute of navigation., pp 615-624

Leandro R, Santos M (2007) A neural network approach for regional vertical total electron content modelling. Stud Geophys Geod 51(2):279-292

Leick A (2004) GPS Satellite Surveying, 3rd edn. New York: John Wiley \& Sons.

Lekutai G (1997) Adaptive Self-tuning neuro wavelet network controllers, PhD thesis. The Electrical Engineering Department, Blacksburg, Virginia

Liu Z, Gao Y (2003) lonospheric TEC predictions over a local area GPS reference network. GPS Solution 8(1):23-29

Liu J, Chen R, Wang Z, Zhang H (2011) Spherical cap harmonic model for mapping and predicting regional TEC. GPS Solutions 15:109-119

Liu J, Chen R, An J, Wang Z, Hyyppa J (2014) "Spherical cap harmonic analysis of the arctic ionospheric TEC for one solar cycle"., J. Geophys. Res. Space Physics 119:601-619. doi:10.1002/2013JA019501

Maruyama T (2007) Regional reference total electron content model over Japan based on neural network mapping techniques. Ann Geophys 25:2609-2614

Misra P, Enge P (2006) Global positioning system: signals, measurements and performance, 2nd edn. Ganga-Jamuna Press, Lincoln, MA, USA

Moon Y (2004) Evaluation of 2-dimensional ionosphere models for national and regional GPS networks in Canada, Master's thesis. University of Calgary, Calgary

Ohashi, Masaharu, Sato, Yutaro, Yamada, Akihiro, Kubo, Yukihiro, Sugimoto, Sueo (2015) "Modeling and Prediction of Regional lonospheric VTEC for Japanese Region by Spherical Cap Harmonic Analysis." Proceedings of the 28th International Technical Meeting of The Satellite Division of the Institute of Navigation (ION GNSS+ 2015), Tampa, Florida, September 2015, pp. 11151122

Oussar Y, Rivals I, Personnaz L, Dreyfus G (1998) Training wavelet networks for nonlinear dynamic input-output modeling. Neurocomputing. 20(1):173-188. do:10.1016/S0925-2312(98)00010-1

Percival D, Walden A (2000) Wavelet Methods for Time Series Analysis (Cambridge Series in Statistical and Probabilistic Mathematics). Cambridge: Cambridge University Press. doi:10.1017/CBO9780511841040

Razin M, Voosogh B, Mohammadzadeh A (2015) Efficiency of artificial neural networks in map of total electron content over Iran, Acta Geodaetica et geophysica.. doi:10.1007/s40328-015-0143-3 
Sayin I, Arikan F, Arikan O (2008) Regional TEC mapping with random field priors and kriging, Radio Sci.. doi:10.1029/2007RS003786

Wielgosz P, Grejner-Brzezinska D, Kashani I (2003) Regional lonosphere mapping with kriging and multiquadric methods. Child J Global Positioning Systems 2(1):48-55

Zhang Q (1997) Using wavelet network in nonparametric estimation. IEEE Trans Neural Netw 8(2):227-236

Zhang Q, Benveniste A (1992) Wavelet networks. IEEE Trans Neural Netw 3(6): 889-898

\section{Submit your manuscript to a SpringerOpen ${ }^{\bullet}$ journal and benefit from:}

- Convenient online submission

Rigorous peer review

- Open access: articles freely available online

- High visibility within the field

- Retaining the copyright to your article

Submit your next manuscript at $\gg$ springeropen.com 